\title{
The omics in migraine
}

\author{
Luana Lionetto ${ }^{*}$, Giovanna Gentile², Elisa Bellei ${ }^{3}$, Matilde Capi ${ }^{1}$, Donata Sabato ${ }^{1}$, Francesco Marsibilio ${ }^{4}$, \\ Maurizio Simmaco ${ }^{1,2}$, Luigi Alberto Pini ${ }^{5}$ and Paolo Martelletti ${ }^{4,6}$
}

\begin{abstract}
The term omics consist of three main areas of molecular biology, such as genomics, proteomics and metabolomics. The omics synergism recognise migraine as an ideal study model, due to its multifactorial nature. In this review, the plainly research data featuring in this complex network are reported and analyzed, as single or multiple factor in pathophysiology of migraine. The future of migraine biomolecular research shall be focused on networking among these different and hierarchical disciplines. We have to look for its Ariadne's tread, in order to see the whole painting of migraine molecular biology.
\end{abstract}

Keywords: Genomics; Proteomics; Metabolomics; Migraine

\section{Review}

The omics synergism

Personalized Medicine aims to evaluate the individual profile of the subject and according to it to proceed to a specific therapeutic strategy.

This strategy is made possible by the shift from a hierarchical to a holistic vision of the biological system. In the first case the control of the biological system is generated from the genome up to the lower hierarchical levels represented by proteomics and metabolomics; in the second case, the interactions among these disciplines are evaluated in a synergic way (Figure 1). This new approach is certainly the most appropriate for the understanding of the physiopathology of migraine that, as a multifactorial disease, can only be assessed through the integrated study of the omics sciences. Nowadays, it is evident that migraine patients react differently to given drugs, but the exact mechanism has not yet been clarified. In this way, genomic and proteomic research aimed to the identification of molecular pathways involved in drug action is of pivotal importance, in order to focus attention of pharmacogenomics studies on the right targets [1].

\section{Genomics}

In an effort to identify genetic variants involved in migraine risk and influencing the appropriate pharmacological

\footnotetext{
* Correspondence: Iuanalionetto@gmail.com

'Sant'Andrea Hospital, Advanced Molecular Diagnostics Unit, Via di Grottarossa 1035 - 1039, Rome 00189, Italy

Full list of author information is available at the end of the article
}

treatments, many genomic studies have been performed in the last years. Due to neurological origin of migraine, some researchers have studied receptors involved in mediation of neuronal activities. Chen et al. [2] characterized one polymorphism in GABRG2 gene encoding the GABAA receptor gamma-2-subunit (rs211037) on a migraine casecontrol population of 546 subjects. No significant correlation was found. Carreno et al. [3] studied the transient receptor potential (TRP) superfamily of non-selective cationic channels accountable of multimodal sensory and pain perception, central and peripheral sensitization, and regulation of calcium homeostasis, relevant steps of migraine physiopathology. They carried out a migraine-control genetic association study genotyping 149 SNPs covering 14 TRP genes. Consistent results were obtained for TRPV3 rs7217270 in the Migraine with aura group and TRPV1 rs222741 in the overall migraine group, suggesting the involvement of the vanilloid TRPV subfamily of receptors to the genetic susceptibility to migraine [4]. Another gene analyzed is the calcium-activated potassium ion channel gene (KCNN3) involved in neural excitability and in migraine susceptibility. Cox et al. [5] performed a gene-wide SNP genotyping in a high-risk genetic isolate from Norfolk Island, characterized by high percentage of migraineurs. A total of 85 SNPs spanning the KCNN3 gene were genotyped in a sub-sample of 285 related individuals. Only four intronic SNPs displayed gene-wide significance: rs4845663, rs7532286, rs6426929 and rs1218551, with the minor allele in each case conferring protection against migraine risk. Using the same population, Cox et al. [6] carried out 


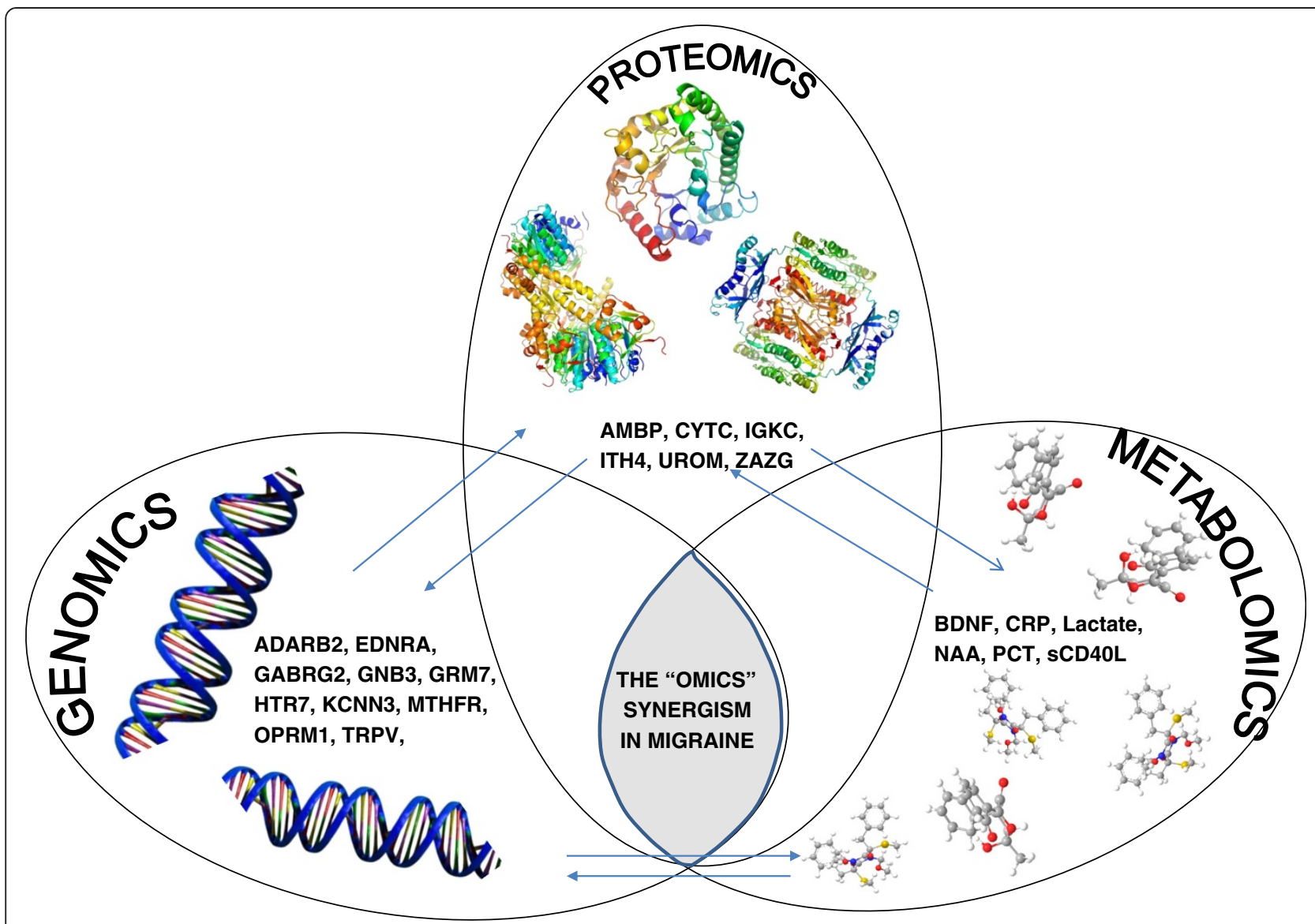

Figure 1 Framework of the multiple interactions taking place in the migraine omics scenario.

another pedigree-based genome-wide association (GWA) study found a significant statistical association with SNP rs4807347 in ZNF555 gene, coding for a zing finger protein. This result has been confirmed in unrelated cohort with more than 500 patients affected by migraine. They also found 4 SNPs in neurotransmitter-related genes (ADARB2, GRM7 and HTR7 genes) suggesting an alteration in the serotoninergic pathway. Maher et al., characterized the entire $\mathrm{X}$ chromosome in an association study on the Norfolk population and provides evidence for the SNP rs102834 in the UTR of the HEPH gene, which is involved in iron homeostasis [7,8]. Ligthart et al. [9] performed a metaanalysis of GWA studies for migraine in six populationbased European cohorts consisting of 2446 cases and 8534 controls. A total of 32 SNPs showed marginal evidence for association to migraine and the best result was obtained for SNP rs9908234 in the nerve growth factor receptor NGFR- gene but those results were not replicated in other cohorts. Besides, they found a modest gene-based significant association between migraine and the rs1835740 near the metadherin gene, but further replication studies did not validated this association $[10,11]$.
The opioid system plays an important role in various biological functions including analgesia, drug response and pain reduction. Menon et al. [12] studied the influence of polymorphism in gene coding for the $\mu$-opioid receptor highlighting the association between the OPRM1 A118G SNP and head pain severity in a clinical cohort of $153 \mathrm{fe}-$ male migraineurs with aura. In particular, G118 allele carriers were more likely to be high pain sufferers compared to homozygous carriers of the A118 allele.

Migraine is a complex condition that may in part be related by endothelial and cerebrovascular disruption [13]. Some studies showed that supplementation of B vitamins lowered homocysteine levels and reduced the occurrence of migraine in women [14]. Besides, polymorphisms in genes coding for key player enzymes in the folate metabolic pathway have been investigated in order to define a relation with the pathology and its treatment. The C677T variant in the methylenetetrahydrofolate reductase (MTHFR) has been associated with increased risk of migraine with aura $[15,16]$. The $\mathrm{C}$ allele carrier is also related to higher reduction in homocysteine levels, severity of pain in migraine and percentage of high migraine disability in patient 
supplemented with B vitamins [14]. The same approach has been adopted for the polymorphism A66G in methionine synthase reductase gene (MTRR): the A allele carriers showed a better response to B vitamin administration [14]. Roecklein et al. [17] performed a haplotype analysis of migraine risk and MTHFR, MTRR and methionine synthase (MTR), including subjects with non-migraine headache $(\mathrm{N}=367)$, migraine without aura $(\mathrm{N}=85)$, migraine with aura $(\mathrm{N}=167)$, and no headache $(\mathrm{N}=1347)$. Haplotype analysis suggested an association between MTRR haplotypes and reduced risk of migraine with aura.

Miao J et al. [18] performed a meta-analysis to determine if polymorphisms in genes linked to the vascular system could be related to migraine. They focused their attention on the receptor for endothelin-1, (EDNRA) known as a potent vasoconstrictor investigating the EDNRA -231G > A SNP. Three studies were included in their meta-analysis for a total of 440 migraineurs, 222 subjects with tension-type headaches (TTHs) and 1323 controls. They found statistical difference between migraineurs and controls with AA genotype vs. $A G+G G$, suggesting a potential association of $-231 G>$ A SNP and migraine. These data suggest that individual SNPs will provide only a small piece of a much larger puzzle composed by a variety of (un) know clinical (phenotypic) information.

Gentile et al. [19] genotyped panel of SNPs involved in triptans pharmacokinetics and pharmacody-namics in a chronic migraine $(\mathrm{CM})$ population. In particular they studied the $30 \mathrm{bp} \mathrm{VNTR} \mathrm{in} \mathrm{MAO} \mathrm{A} \mathrm{(monoamine} \mathrm{oxidase}$ A) promoter, CYP $1 \mathrm{~A} 2$ " $1 \mathrm{C}$ and "1 F, CYP3A4 "1B and C825T SNP in the gene coding the G protein b3 subunit (GNB3). A significant association with $\mathrm{CM}$ was found for the long allele of monoamine oxidase A $30 \mathrm{bp}$ VNTR and CYP1A2*1 $\mathrm{F}$ variant. The same authors performed an analysis of the association between genotypic and allelic frequencies of the analyzed SNPs and the grade of response to triptan administration: a significant correlation for MAOA uVNTR polymorphism was found. Further stratification of patients in abuser and non-abuser groups revealed a significant association with triptan overuse and, within the abusers, with drug response to the CYP1A2*1 F variant [20].

\section{Proteomics}

With the completion of the human genome project in 2002 , it has become clear that organism complexity is generated more by a complex proteome than by a complex genome.

Actually, the term "clinical proteomics" defines proteomic technologies employed to examine clinical samples [21]. The available genomic data have now been translated to proteomics, making the discovery of biomarkers increasingly feasible. With its high-throughput and unbiased approach to the analysis of variation in protein expression patterns (actual phenotypic expression of genetic variation), proteomics promises to be the most suitable platform for biomarker discovery. This hopefulness is based on the increasing advances and ability of proteomic technologies to identify thousands of proteins and peptides in complex biological tissues and biofluids, such as plasma, serum and urine [22]. In the past decade, many novel proteomic technologies were emerged and applied to several biological systems for the understanding of cellular activities, disease development and physiological responses to therapeutic interventions and environmental perturbations [23]. One of such emerging field is the application of proteomic technologies to toxicological research, which has given rise to a new area called toxicoproteomics [24]. Drug induced toxicity represents a significant problem in healthcare delivery, therefore the early detection of organ toxicity may provide great benefits to patients, preventing further onset of adverse events and complications of disease management. Incidences of toxicity in liver, heart, brain, kidney and other organs have been reported with the use of different therapeutic drugs. In particular, various epidemiologic investigations proved that different drug types could cause nephrotoxicity, especially in chronic patients.

In this regard, Bellei and co-authors reported two proteomic studies in which they analysed the urinary proteome of medication-overuse headache $(\mathrm{MOH})$ patients, in comparison with healthy non-abuser individuals as control, with the purpose to identify possible differences in excreted proteins induced by the excessive consumption of antimigraine drugs, that could lead to nephrotoxicity $[25,26]$. Comparing the proteomic profiles of patients and controls, they found a significantly different protein expression at various MW levels, especially in the NSAIDs group, in which six proteins over-secreted from kidney were strongly correlated with various forms of kidney disorders: uromodulin (UROM), alpha-1-microglobulin (AMBP), zinc-alpha-2-glycoprotein (ZAZG), cystatin C (CYTC), Ig-kappa-chain (IGKC), and inter-alpha-trypsin heavy chain H4 (ITIH4). These preliminary results have allowed to define the urinary protein pattern of $\mathrm{MOH}$ patients, that was found to be correlated to the abused drug. While adverse effects from long-term triptans use are unknown, the overuse of analgesics may cause wellknown unwanted events, including liver dysfunction, gastrointestinal bleeding, addiction and renal insufficiency [27]. Moreover, a recent review concerning the epidemiology of drug-induced disorders has demonstrated that medication overuse could lead to nephrotoxicity and potential renal damage [28]. Currently, the most pertinent application in nephrotoxicology is the proteomic analysis of urine. In recent years, it has proposed a broad range of urinary enzymes and proteins as possible early biomarkers of drug-induced nephrotoxicity [29-31]. 


\section{Metabolomics}

While the genomics and proteomics suggest a possible mode of operation of the system, metabolomics gives the actual representation of the system. In agreement with the multifactorial nature of the disease, the studies conducted to date relate to different classes of analytes. In fact, several different mechanisms, such as neuro-inflammatory, neurological and cerebrovascular, have so far been suggested in migraine pathophysiology [32].

Whereas the presence of inflammatory processes during migraine attacks, serum levels of different proinflammatory molecules have been investigated. Several studies have found elevated levels of C-Reactive Protein (CRP), a marker of chronic low-grade inflammation, in patients with migraine [33,34]. Also the procalcitonin levels were investigated as indicators of inflammation in migraine patients with and without aura. Turan et al. found significantly high levels of PCT in patients with migraine during the attack compared to the interictal period $(0.0485$ vs $0.0298 \mathrm{ng} / \mathrm{ml})$ [35]. An interesting fact was found by Guldiken et al. about the increase of soluble CD40 ligand (sCD40L). In this study, sCD40L amount was higher in the subgroup of migraineurs with aura than in those without aura and in rare attacks rather than in the frequent ones. In both comparisons the difference in the levels of sCD40L was not significant but these data may be related to the association of migraine with cardiovascular diseases [36].

Also the correlation between migraine and molecules of pain was investigated. Several observation suggested a relationship between low serum levels of vitamin D and higher incidence of chronic pain [37,38]. However, in a large cross-sectional study, Kjaergaard et al. have found that low level of serum vitamin D were associated with nonmigraine type of headache [39]. Further studies should be conducted to clarify the potential association of vitamin $\mathrm{D}$ and migraine pain. Brain-derived neurotrophic factor (BDNF) is a neurotrophin associated with pain modulation and central sensitization [40]. Fisher et al. have demonstrated that in migraineurs, BDNF was significantly elevated during migraine attacks $(31.24 \pm 9.31 \mathrm{ng} / \mathrm{ml}) \mathrm{com}$ pared with headache-free periods $(24.50 \pm 9.17 \mathrm{ng} / \mathrm{ml})$, tension-type headache $(20.97 \pm 2.49 \mathrm{ng} / \mathrm{ml})$ and healthy controls $(21.20 \pm 5.64 \mathrm{ng} / \mathrm{ml})$ [41]. This study, showing a correlation between migraine and BDNF, supports the hypothesis that BDNF has a role in the pathophysiology of migraine. The results are in agreement with a pilot study of Tanure et al. [42].

However, NMR or mass spectrometry techniques are able to provide, with an acceptable probability, the description of the current biochemical state of an organism. The development of proton magnetic resonance spectroscopy $\left({ }^{1} \mathrm{H}\right.$-MRS $)$ has been used to assess noninvasively the metabolic status of human brain [43]. Several studies have employed ${ }^{1} \mathrm{H}$-MRS achieving numerous results for metabolites including $\mathrm{N}$-acetylaspartate (NAA), as a marker of neuronal functioning [44], choline (Cho), as a marker for membrane turnover [45], total creatine $(\mathrm{tCr})$ and lactate, for energy metabolism [46], and myo-inositol (a glial marker) [47]. With the exception of NAA, the results obtained for these molecules are heterogeneous and sometimes contradictory. Indeed the levels of NAA are also increased in the serum [48]. In our opinion, to date, it has not been identified molecules that can be used as a marker for migraine.

Undoubtedly, spectroscopy Nuclear Magnetic Resonance and Mass Spectrometry represent the most powerful and most widely used techniques for the simultaneous analysis of different molecules, allowing together with functional genomics and proteomics to open new roads knowledge in the pathophysiology of migraine. We can suppose that also the progression of the disease may be evaluated by a therapeutic metabolite monitoring approach [49].

\section{Conclusions}

A conclusive scene of omics network in migraine pathophysiology is still far to be sharpened. We know a lot of genomics, but less of proteomics and metabolomics of migraine. However, there are numerous scientific evidences assigning an increasingly dominant role to external factors, environmental or behavioural, that interact with the pathophysiology of migraine. Although genomics represents the hierarchical basis of migraine mechanism, proteomics and metabolomics mirror its real image. We have to continue to study the connections among omics in order to unsnarl the Ariadne's tread of migraine.

\section{Abbreviations}

SNP: Single nucleotide polymorphism; CM: Chronic migraine; $\mathrm{MOH}$ : Medication-overuse headache; MW: Molecular weight; NSAIDs: Nonsteroidal anti-inflammatory drugs; PCT: Procalcitonin; NMR: Nuclear magnetic resonance.

\section{Competing interests}

All authors declared no competing interest related to the content of this manuscript.

\section{Authors' contributions}

$L L, G G, E B$ contributed equally in the preparation of the manuscript. LAP and PM conceived the study, provided overall and oversaw the implementation of the study. All the authors approved the final draft of the manuscript. No external assistance in selection, writing or reviewing data has been utilized.

\section{Author details}

${ }^{1}$ Sant'Andrea Hospital, Advanced Molecular Diagnostics Unit, Via di Grottarossa 1035 - 1039, Rome 00189, Italy. ${ }^{2}$ NESMOS Department, Sapienza University of Rome, Rome, Italy. ${ }^{3}$ Department of Diagnostic Medicine, Clinic and Public Health, University of Modena and Reggio Emilia, Modena, Italy.

${ }^{4}$ Regional Referral Headache Centre, Sant'Andrea Hospital, Rome, Italy. ${ }^{5}$ Inter-Department Headache and Drug Abuse Centre, University of Modena and Reggio Emilia, Modena, Italy. ${ }^{6}$ Department of Clinical and Molecular Medicine, Sapienza University of Rome, Rome, Italy.

Received: 6 June 2013 Accepted: 22 June 2013

Published: 1 July 2013 


\section{References}

1. Simmaco M, Borro M, Missori S, Martelletti P (2009) Pharmacogenomics in migraine: catching biomarkers for a predictable disease control. Expert Rev Neurother 9(9):1267-1269

2. Chen T, Murrell M, Fowdar J, Roy B, Grealy R, Griffiths LR (2012) Investigation of the role of the GABRG2 gene variant in migraine. J Neurol Sci 318(1-2):112-114, 15

3. Carreño O, Corominas R, Fernández-Morales J, Camiña M, Sobrido MJ, Fernández-Fernández JM, Pozo-Rosich P, Cormand B, Macaya A (2012) SNP variants within the vanilloid TRPV1 and TRPV3 receptor genes are associated with migraine in the Spanish population. Am J Med Genet B Neuropsychiatr Genet 159B(1):94-103

4. Geppetti P, Rossi E, Chiarugi A, Benemei S (2012) Antidromic vasodilatation and the migraine mechanism. J Headache Pain 13(2):103-111

5. Cox HC, Lea RA, Bellis C, Carless M, Dyer T, Blangero J, Griffiths LR (2011) Variants in the human potassium channel gene (KCNN3) are associated with migraine in a high risk genetic isolate. J Headache Pain 12(6):603-608

6. Cox HC et al (2012) A genome-wide analysis of 'Bounty' descendants implicates several novel variants in migraine susceptibility. Neurogenetics 13(3):261-266

7. Maher BH, Lea RA, Benton M, Cox HC, Bellis C, Carless M, Dyer TD, Curran J, Charlesworth JC, Buring JE, Kurth T, Chasman DI, Ridker PM, Schürks M, Blangero J, Griffiths LR (2012) An X chromosome association scan of the Norfolk Island genetic isolate provides evidence for a novel migraine susceptibility locus at Xq12. PLoS One 7(5):e37903

8. Schürks M (2012) Genetics of migraine in the age of genome-wide association studies. J Headache Pain 13(1):1-9

9. Ligthart L, de Vries B, Smith AV, Ikram MA, Amin N, Hottenga JJ, Koelewijn SC, Kattenberg VM, de Moor MH, Janssens AC, Aulchenko YS, Oostra BA, de Geus EJ, Smit JH, Zitman FG, Uitterlinden AG, Hofman A, Willemsen G, Nyholt DR, Montgomery GW, Terwindt GM, Gudnason V, Penninx BW, Breteler M, Ferrari MD, Launer LJ, van Duijn CM, van den Maagdenberg AM, Boomsma DI (2011) Meta-analysis of genome-wide association for migraine in six population-based European cohorts. Eur J Hum Genet 19(8):901-907

10. Sintas C, Carreño O, Fernández-Morales J, Cacheiro P, Sobrido MJ, Narberhaus B, Pozo-Rosich P, Macaya A, Cormand B (2012) A replication study of a GWAS finding in migraine does not identify association in a Spanish case-control sample. Cephalalgia 32(14):1076-1080

11. Esserlind AL, Kirchmann M, Hauge AW, Le H, Olesen J (2012) A genotypephenotype analysis of the 8q22.1 variant in migraine with aura. Eur J Neurol 19(4):603-609

12. Menon S et al (2012) The human $\mu$-opioid receptor gene polymorphism (A118G) is associated with head pain severity in a clinical cohort of female migraine with aura patients. J Headache Pain 13(7):513-519

13. Tana C, Tafuri E, Tana M, Martelletti P, Negro A, Affaitati G, Fabrizio A, Costantini R, Mezzetti A, Giamberardino MA (2013) New insights into the cardiovascular risk of migraine and the role of white matter hyperintensities: is gold all that glitters? J Headache Pain 14(1):9, 1

14. Menon S, Lea RA, Roy B, Hanna M, Wee S, Haupt LM, Oliver C, Griffiths LR (2012) Genotypes of the MTHFR C677T and MTRR A66G genes act independently to reduce migraine disability in response to vitamin supplementation. Pharmacogenet Genom 22(10):741-9

15. Scher Al, Terwindt GM, Verschuren WM et al (2006) Migraine and MTHFR C677T genotype in a population-based sample. Ann Neurol 59(2):372-375

16. Samaan Z, Gaysina D, Cohen-Woods S, Craddock N, Jones L, Korszun A, Owen M, Mente A, McGuffin P, Farmer A (2011) Methylenetetrahydrofolate reductase gene variant (MTHFR C677T) and migraine: a case control study and meta-analysis. BMC Neurol 11:66, 2

17. Roecklein KA, Scher Al, Smith A, Harris T, Eiriksdottir G, Garcia M, Gudnason $\checkmark$, Launer $L$ (2013) Haplotype analysis of the folate-related genes MTHFR, MTRR, and MTR and migraine with aura. Cephalalgia 33(7):469-482

18. Miao J, Wang F, Fang Y (2012) Association of $231 \mathrm{G}>$ A polymorphism of endothelin type A receptor gene with migraine: a meta-analysis. J Neurol Sci 323(1-2):232-235, 15

19. Gentile G, Missori S, Borro M, Sebastianelli A, Simmaco M, Martelletti P (2010) Frequencies of genetic polymorphisms related to triptans metabolism in chronic migraine. J Headache Pain 11(2):151-156

20. Gentile G, Borro M, Lala N, Missori S, Simmaoc M, Martelletti P (2010) Genetic polymorphisms related to efficacy and overuse of triptans in chronic migraine. J Headache Pain 11(5):431-435

21. Aldred S, Grant MM, Griffiths HR (2004) The use of proteomics for the assessment of clinical samples in research. Clin Biochem 37:943-952
22. Veenstra TD, Conrads TP, Hood BL, Avellino AM, Ellenbogen RG, Morrison RS (2005) Biomarkers: mining the biofluid proteome. Mol Cell Proteomics 4:409-418

23. Gao Y, Holland RD, Yu LR (2009) Quantitative proteomics for drug toxicity. Briefings Funct Genomics Proteomics 8(2):158-166

24. Wetmore BA, Merrick BA (2004) Toxicoproteomics: proteomics applied to toxicology and pathology. Toxicol Phatol 32:619-642

25. Bellei E, Cuoghi A, Monari E, Bergamini S, Fantoni LI, Zappaterra M, Guerzoni S, Bazzocchi A, Tomasi A, Pini LA (2012) Proteomic analysis of urine in medication-overuse headache patients: possibile relation with renal damages. J Headache Pain 13:45-52

26. Bellei E, Monari E, Cuoghi A, Bergamini S, Guerzoni S, Ciccarese M, Ozben T, Tomasi A, Pini LA (2013) Discovery by a proteomic approach of possible early biomarkers of drug-induced nephrotoxicity in medication-overuse headache. J Headache Pain 14:6

27. Robbins L (2004) Frequent triptan use: observations on safety issues. Headache 44:178-182

28. Taber SS, Pasko DA (2008) The epidemiology of drug-induced disorders: the kidney. Expert Opin Drug Saf 7(6):679-690

29. Gonzáles-Buitrago JM, Ferreira L, Lorenzo I (2007) Urinary proteomics. Clin Chim Acta 375:49-56

30. Sleno L, Emili A (2008) Proteomic methods for drug target discovery Curr Opin Chem Biol 12:46-54

31. Waring WS, Moonie A (2011) Earlier recognition of nephrotoxicity using novel biomarkers of acute kidney injury. Clin Toxicol 49:720-728

32. Bahra A, Matharu MS, Buchel C, Frackowiak RS, Goadsby PJ (2001) Brainstem activation specific to migraine headache. Lancet 357(9261):1016-1017, 31

33. Vanmolkot FH, de Hoon JN (2007) Increased C-reactive protein in young adult patients with migraine. Cephalalgia 27(7):843-846

34. Welch KM, Brandes AW, Salerno L, Brandes JL (2006) C-reactive protein may be increased in migraine patients who present with complex clinical features. Headache 46(2):197-199

35. Turan H, Horasanli B, Ugur M, Arslan H (2011) Procalcitonin levels in migraine patients. Can J Neurol Sci 38(1):124-128

36. Guldiken S, Guldiken B, Demir M, Kabayel L, Ozkan H, Turgut N, Hunkar R, Kat S (2011) Soluble CD40 ligand and prolactin levels in migraine patients during interictal period. J Headache Pain 12(3):355-360

37. Turner MK, Hooten WM, Schmidt JE, Kerkvliet JL, Townsend CO, Bruce BK (2008) Prevalence and clinical correlates of vitamin D inadequacy among patients with chronic pain. Pain Med 9(8):979-984

38. Prakash S, Mehta NC, Dabhi AS, Lakhani O, Khilari M, Shah ND (2010) The prevalence of headache may be related with the latitude: a possible role of Vitamin D insufficiency? J Headache Pain 11(4):301-307

39. Kjaergaard M, Eggen AE, Mathiesen EB, Jorde R (2012) Association Between Headache and Serum 25-Hydroxyvitamin D; the Tromsø Study: Tromsø 6. Headache 13. doi:10.1111/j.1526-4610.2012.02250.x

40. Thompson SW, Bennett DL, Kerr BJ, Bradbury EJ, McMahon SB (1999) Brainderived neurotrophic factor is an endogenous modulator of nociceptive responses in the spinal cord. Proc Natl Acad Sci USA 96(14):7714-7718, 6

41. Fischer M, Wille G, Klien S, Shanib H, Holle D, Gaul C, Broessner G (2012) Brain-derived neurotrophic factor in primary headaches. J Headache Pain 13(6):469-475

42. Tanure MT, Gomez RS, Hurtado RC, Teixeira AL, Domingues RB (2010) Increased serum levels of brain-derived neurotropic factor during migraine attacks: a pilot study. J Headache Pain 11(5):427-430

43. Bittšanský M, Výbohová D, Dobrota D (2012) Proton magnetic resonance spectroscopy and its diagnostically important metabolites in the brain. Gen Physiol Biophys 31(1):101-112

44. Sarchielli P, Tarducci R, Presciutti O, Gobbi G, Pelliccioli GP, Stipa G, Alberti A, Capocchi G (2005) Functional 1H-MRS findings in migraine patients with and without aura assessed interictally. Neurolmage 24(4):1025-1031, 15

45. Reyngoudt H, De Deene Y, Descamps B, Paemeleire K, Achten E (2010) $1 \mathrm{H}$ MRS of brain metabolites in migraine without aura: absolute quantification using the phantom replacement technique. Magn Reson Mater Phys 23 (4):227-241

46. Reyngoudt H, Paemeleire K, Dierickx A, Descamps B, Vandemaele P, De Deene Y, Achten E (2011) Does visual cortex lactate increase following photic stimulation in migraine without aura patients? A functional (1)H-MRS study. J Headache Pain 12(3):295-302

47. Dichgans M, Herzog J, Freilinger T, Wilke M, Auer DP (2005) 1H-MRS alterations in the cerebellum of patients with familial hemiplegic migraine type 1. Neurology 64(4):608-613 
48. De Tommaso M, Ceci E, Pica C, Trojano M, Delussi M, Franco G, Livrea P, Ruggieri M (2012) Serum levels of $\mathrm{N}$-acetyl-aspartate in migraine and tension-type headache. J Headache Pain 13(5):389-394

49. Lionetto L, Capi M, Vignaroli G, Negro A, Martelletti P (2012) Deciphering the task of $\mathrm{N}$-acetyl aspartate in migraine. Expert Rev Neurother 12 (9):1057-1059

doi:10.1186/1129-2377-14-55

Cite this article as: Lionetto et al:: The omics in migraine. The Journal of Headache and Pain 2013 14:55.

Submit your manuscript to a SpringerOpen ${ }^{\circ}$ journal and benefit from:

- Convenient online submission

- Rigorous peer review

- Immediate publication on acceptance

- Open access: articles freely available online

- High visibility within the field

- Retaining the copyright to your article 